https://doi.org/10.7203/Normas.2.4662

\title{
EL TRATAMIENTO DE LA PUNTUACIÓN EN LOS LIBROS DE ESTILO PERIODÍSTICOS
}

\author{
THE TREATMENT OF PUNCTUATION IN THE NEWSPAPER STYLE GUIDES
}

Jorge ROSELLÓ VERDEGUER

UNED-Valencia

\section{RESUMEN:}

Los signos de puntuación son un elemento fundamental para organizar y entender la información que leemos y escuchamos en los medios de comunicación. En este artículo se analiza el tratamiento que los libros de estilo periodísticos realizan de la puntuación y cuál es la importancia que conceden al tema. En concreto, nos centramos en los libros de estilo de los diarios El País, El Mundo, ABC y del grupo de comunicación Vocento. Analizamos, igualmente, el enfoque que sobre los signos de puntuación realizan los medios audiovisuales (radio y televisión), y lo hacemos a través de un manual sobre redacción y locución en radio y del Manual de estilo de TVE.

PALABRAS CLAVE: libro de estilo, oralidad, escritura, normativa, signos de puntuación.

\section{ABSTRACT:}

Punctuation marks are very important for the proper organization and comprehension of the information we read and listen to in the media. This article analyzes how various manuals of style in Spanish press treat punctuation. The manuals analyzed specifically correspond to $E l$ País, El Mundo, ABC and the Vocento media group. This article also analyses the approach on punctuation carried out by editorial staffs as well as radio and television broadcasters according to the Manual de estilo de TVE.

KEY WORDS: style guide, orality, writing, rules, punctuation.

NORMAS. REVISTA DE ESTUDIOS LINGÜÍSTICOS HISPÁNICOS, NÚMERO 2 (AÑO 2012):

http://www.uv.es/normas

(ISSN 2174-7245). 


\section{INTRODUCCIÓN}

Hoy en día, los medios de comunicación son los encargados de difundir el idioma y su buen uso. Gómez Font (2001) alberga pocas dudas sobre quiénes dictan las normas de uso del español actualmente: no son los diccionarios, ni las gramáticas, ni los libros de ortografía, sino que las verdaderas guías de uso del idioma son los manuales de estilo, que en su mayor parte pertenecen a los medios de comunicación, tanto escritos como orales. Cualquier aproximación que se haga al estudio del español deberá tener en cuenta este tipo de publicaciones, a cargo de expertos en la lengua que van resolviendo las dudas que plantea el idioma.

Es muy difícil dar un concepto único de libro de estilo. Tomando como referencia diversas definiciones extraídas de diccionarios de periodismo, Fernández de Beaumont (1987: 38) señala tres características comunes. En primer lugar, todas las definiciones hacen hincapié en la condición de conjunto de normas, lo que quiere decir que un libro de estilo se presenta como algo normativo. En segundo lugar, estas normas se utilizan para la redacción de noticias. Y, por último, tienen como finalidad unificar criterios ortográficos y presentar adecuadamente los originales.

Hay que tener en cuenta que un libro de estilo se crea, fundamentalmente, para ayudar a fijar la identidad del periódico y no solo como recordatorio de las normas ortográficas y de escritura más importantes. Por esa razón, Cebrián (1981: 32) señala que un libro de estilo periodístico no garantiza la belleza del idioma ni es un manual para aprender a escribir. Sus reglas se refieren más bien a la pureza y corrección gramatical del lenguaje empleado; a la manera de utilizar los diversos tratamientos (yo, usted...), según las ocasiones; al modo de escribir las cifras (en letras o guarismos); al significado o empleo de las siglas; a la traducción de palabras o nombres extranjeros y cosas de este tipo. No obstante, también deja bien claro que un libro de estilo no es una gramática ni un diccionario al uso. Es, simplemente, un código interno de una redacción de cualquier medio informativo que trata de unificar sistemas y formas expresivas con el fin de dar personalidad al propio medio y facilitar la tarea del lector.

En cualquier caso, en la mayoría de los libros de estilo, se hace hincapié en el hecho de que sus páginas no pretenden ser una gramática o una guía de composición retórica, pues se supone que un periodista conoce las normas gramaticales cuando escribe sus artículos. Si acaso, el libro de estilo puede aclarar ciertos puntos difíciles o discutibles, interpretar algunas normas que resulten ambiguas o explicar ciertos usos ya aceptados en el idioma.

Por otro lado, los signos de puntuación siempre han sido tratados como un aspecto de la ortografía, un aspecto menor en muchos casos, ya que suele creerse que la puntuación no se rige por normas precisas que puedan ser aplicadas en cualquier 
circuntancia, como sí ocurre con las normas ortográficas, y, por consiguiente, dependen del gusto de cada autor. Sin negar que existe un cierto margen de libertad en el uso de algunos signos de puntuación en determinadas circunstancias, su utilización se rige por un conjunto de normas que se recogen en la Ortografía académica y que los libros de estilo se encargan de recordar. En este sentido, Grijelmo (2008: 268), responsable de varios trabajos destinados a la escritura periodística, señala:

Un criterio muy extendido entre los profesionales parte de que el uso de los signos de puntuación depende del gusto de cada autor. Y no. Muy al contrario: los signos de puntuación están íntimamente ligados a la gramática y a la sintaxis. La lengua debe dejar pocos resquicios para el libre albedrío personal, puesto que la comunicación eficaz depende de que los signos que sirven al autor para expresarse coincidan con la descodificación que de ellos hace el receptor del mensaje. Otra cuestión vendrá dada por el gusto en el ritmo, la metáfora, las palabras...

Algunos lingüistas han observado con detalle el uso de la puntuación en la prensa diaria. Peñalver (2009), por ejemplo, recopila los errores más frecuentes que afectan al uso de los signos de puntuación, signos de entonación y auxiliares. Realizamos aquí un breve resumen de su trabajo:

1. Ausencia de comas entre transpositores para señalar adecuadamente la oración incrustada o intercalada:

La explicación demagógica de que se quiere abaratar el precio no resiste el menor análisis, porque si el Gobierno estuviese preocupado por el valor de los libros de texto bien podría fijar un precio único, asequible, dejando que las editoriales compitieran en calidad y en contenidos ante los profesores y las autoridades educativas (El País Andalucía, 1 de julio de 2000).

2. Ausencia de comas para señalar estructuras y construcciones absolutas intercaladas:

Cualquier idea que se le ocurriera a un progresista hacía temblar a los banqueros, pero lentamente el campo magnético de la seducción fue cambiando y agotada toda su carga aquella generación cayó en la tumba junto con sus guitarras (El País, 8 de julio de 2001).

3. Ruptura de la relación entre el sujeto y el verbo o el verbo y el complemento directo por la presencia injustificada de una coma:

NORMAS. REVISTA DE ESTUDIOS LINGÜÍSTICOS HISPÁNICOS, NÚMERO 2 (AÑO 2012):

http://www.uv.es/normas

(ISSN 2174-7245). 
Los terroristas que empotraron los aviones contra las fachadas de los rascacielos, fueron turistas muy respetados en España ( $A B C, 15$ de octubre de 2002).

\section{Uso erróneo del punto en lugar de los dos puntos:}

José Javier Esparza, el extraordinario columnista de Televisión del Grupo Correo -sus críticas y comentarios son columnas de Opinión tan bien escritas como inteligentes-, ha dividido los programas informativos de las principales cadenas españolas en tres grupos. El favorable al Gobierno, con TVE 1 y Antena 3 como baluartes de la proximidad al poder gubernativo. El independiente, con Tele 5 -Grupo Correo-, y la 2, y el antiGobierno con Canal Plus como exponente principal ( $A B C, 6$ de julio de 2001).

5. Ausencia de coma antes de sin embargo cuando va precedido de un conector copulativo:

Y sin embargo, la sensación de fondo es que se le escapó el conjunto del debate (ABC, 14 de abril de 2009).

\section{Ausencia del signo de interrogación de apertura:}

Cómo puede ser que nosotros, personas que nos preciamos de críticas, individuos de buen gusto, libres y autónomos, inmunes e impenetrables al bombardeo publicitario, podamos someternos dócilmente, como perritos amaestrados, a las arbitrarias indicaciones de la moda? (Magazine de La Razón, 13 de octubre de 2002).

7. Uso de las comillas en estructuras oracionales de estilo indirecto introducidas por el transpositor que:

Asegura ante la Asociación Nacional de Periódicos que «los nacionalistas dan justificación ideológica a los asesinos» (El Mundo, 28 de noviembre de 2000).

Peñalver (2009: 37-38) concluye que los agentes sociales (la escuela, la prensa, la Administración) deben cuidar más todos los aspectos relacionados con la ortografía, y añade que, para mejorar la expresión escrita, debe recuperarse la figura del corrector. En lo referente a la puntuación, señala que lo que caracteriza un buen estilo periodístico (claridad, precisión, concisión y naturalidad) depende mucho del buen uso de la ortografía de la puntuación. Por último, se sorprende de la escasa presencia en los textos de un signo de puntuación tan importante como el punto y coma, pues son muy pocos los articulistas que lo usan adecuadamente. 


\section{LA PUNTUACIÓN EN LOS MEDIOS DE COMUNICACIÓN}

Vamos a analizar en las siguientes páginas el tratamiento que realizan de los signos de puntuación algunos libros de estilo publicados en España. Uno de los problemas a la hora de abordar la normativa de los signos es la dicotomía existente entre oralidad y escritura. Como sabemos, la puntuación tiene como finalidad organizar y jerarquizar la información del texto escrito, por lo que su normativa se rige fundamentalmente por criterios sintácticos y discursivos. La puntuación, señala la actual Ortografía (2010: 287), proporciona información de tipo gramatical y pragmático, de modo que, cuando «se escribe un punto, se indica que en ese lugar terminan un enunciado, un párrafo o un texto». Pero, igualmente, el uso de los signos se ha relacionado a elementos prosódicos (en concreto, a la pausa y a la entonación). De hecho, la puntuación nace originariamente con el fin de marcar las pausas necesarias para respirar en los tiempos en que la lectura no era silenciosa y el texto se leía en voz alta. Por ello, nos ha parecido interesante separar estas dos funciones de los signos y analizar, por un lado, el tratamiento que sobre los signos de puntuación realiza la prensa escrita, en concreto los diarios El País, El Mundo y $A B C)^{1}$, cuyos libros de estilo pueden ser consultados por cualquier interesado en el tema, y el trabajo de Martínez de Sousa (2003) sobre los diarios del grupo Vocento (El Diario Vasco, el Norte de Castilla, Las Provincias, El Sur...). Por otro lado, hemos examinado la visión que sobre el tema tienen los medios de comunicación orales, tanto en radio, en donde seguimos el trabajo de Bailén y Perona (1999) sobre locución en el medio radiofónico, como en televisión, con el Manual de estilo de TVE (1993).

Estudiamos aquí con cierta amplitud los signos que la mayoría de la crítica (Halliday, 1985; Catach, 1994; Figueras, 2001) considera signos principales o de primer orden (punto y aparte, punto y seguido, punto y coma, dos puntos y coma), aunque también nos referiremos brevemente a los demás.

${ }^{1}$ Aunque no lo reseñamos aquí expresamente, debido a que el tratamiento que hace de la puntuación reproduce básicamente lo establecido en las normas de la RAE, sí queremos hacer mención aquí del Manual del español urgente, de la agencia EFE, trabajo pionero en cuestiones normativas dirigidas a los medios de comunicación.

NORMAS. REVISTA DE ESTUdIOS LINGÜÍSTICOS HISPÁNICOS, NÚMERO 2 (AÑO 2012):

http://www.uv.es/normas

(ISSN 2174-7245). 


\section{LIBROS DE ESTILO PERIODÍSTICOS}

\subsection{Libro de estilo de El País (2002)}

Este manual dedica a los signos de puntuación todo un capítulo, el número 11 (páginas 117-139), que lleva el título de «Signos ortográficos», y estudia la coma, el punto, el punto y coma, los dos puntos, las comillas, el paréntesis, los corchetes, el guion, la barra, los signos de interrogación y exclamación, el apóstrofo, los puntos suspensivos, el asterisco y la cedilla. También se incluyen en este capítulo todas las cuestiones relativas a los acentos, las mayúsculas y las minúsculas.

En el epígrafe 11.1, relativo a la coma, señala que las reglas para el uso «están tomadas fundamentalmente de la Gramática de la lengua española editada por la Academia (Madrid, 1959), con algunas explicaciones adicionales». Hay que suponer que las reglas de las que habla no se refieren solo a la coma, sino también a los restantes signos de puntuación que en este libro se analizan. En todo caso, llama la atención que en esta edición del año 2002 todavía sigan basándose en la Gramática del año 1959, como en otras ediciones anteriores, y no en tratados posteriores.

A la coma destina once apartados. La mayoría de ellos recuerdan las normas básicas de este signo de puntuación (enumeraciones, incisos, elipsis del verbo, vocativos, etc.). Especial importancia tiene el epígrafe nueve, en donde se hace referencia a tres tipos de errores que se cometen con «harta frecuencia en el uso de la coma». Son, en sustancia, casos de ambigüedad no contemplados en muchos tratados ortográficos, pero sí en manuales ${ }^{2}$ especialmente destinados a periodistas, pues estos errores parecen ser frecuentes en la prensa escrita:

a) Antes del adverbio como, este signo ortográfico cambia el significado en muchas oraciones. No es igual No lo hice como me dijiste (lo hizo de distinta forma) que No lo hice, como me dijiste (no lo hice, luego cumplió el encargo).

b) Aplicada a ciegas, la norma de encerrar entre comas un nombre propio, cuando lo que le precede en la oración es el cargo o condición de la persona nombrada, lleva al error. No es lo mismo escribir El capitán José Fernández ha sido condecorado que El capitán, José Fernández, ha sido condecorado. Tal como está redactado el segundo de los ejemplos, José Fernández es el único capitán que existe.

c) Cuando se omite antes de un complemento circunstancial y altera la concordancia. Ejemplos: El general pidió orden durante su toma de posesión

${ }^{2}$ Es el caso del libro de Grijelmo (2008), en donde se aborda el uso de la coma delante de la conjunción $y$, la coma después de luego o mientras, etc.

NORMAS. REVISTA DE ESTUDIOS LINGÜÍSTICOS HISPÁNICOS, NÚMERO 2 (AÑO 2012)

http://www.uv.es/normas

(ISSN 2174-7245). 
y El general pidió orden, durante su toma de posesión. En el primer caso, solamente reclamaba orden para el acto en el que tomaba posesión. En el segundo pide orden en términos generales, y la petición se produce durante el citado acto.

Recomienda eliminar la coma siempre que se pueda, sobre todo, en las frases cortas. Por último, señala que hay que evitar el error de convertir en una oración con verbo elidido aquellos títulos simplemente enunciativos que enmarcan un escrito. El general en su laberinto no puede ser El general, en su laberinto. El fútbol antes de la guerra no podría convertirse en El fútbol, antes de la guerra.

Por lo que hace referencia al punto, el Libro de estilo resume su uso en seis epígrafes, sin distinguir entre punto y seguido, punto y aparte y punto final, ni hacer referencia (como sí lo hace en otros signos) a las pausas o la entonación. Indica que se emplea punto «para indicar el final de una oración, para marcar los millares en las cantidades numéricas escritas con cifras, en las fracciones de hora y para las iniciales de nombres o apellidos». También aborda la combinación del punto con otros signos (paréntesis, rayas, comillas, dos puntos y puntos suspensivos):

- El punto va detrás del paréntesis, de la raya o de las comillas de cierre cuando cualquiera de estos signos se haya abierto inmediatamente después de un punto. Nunca se suprimirán el paréntesis, el corchete o las comillas de cierre por el hecho de coincidir con el punto al final de una oración.

- Después de los puntos suspensivos («que son tres, y nada más que tres», recuerda el Libro) no se pone punto final. Tampoco después de los signos de interrogación o de admiración.

También recuerda que no se debe emplear punto en las siglas (salvo cuando formen parte de un texto todo escrito en mayúsculas), en los números de años o en los teléfonos, y que, en el caso de enumeraciones escritas en distintos párrafos, cada uno de ellos llevará el punto final.

Hay, por último, cuestiones relativas al formato periodístico, como son los titulares, las firmas y los ladillos. Así, en el apartado 11.17, establece que no se pondrá punto final a los titulares, las firmas y los ladillos no engatillados (los engatillados sí, puesto que forman parte del párrafo que encabezan). Un pie de foto, aunque conste de una sola oración, llevará punto final.

Seis epígrafes dedica también este manual al punto y coma. Dice de él que señala pausa y descenso en la entonación; no como el punto, que cierra una oración completa, sino como mero reposo entre dos o más miembros de esta. Se trata, afirma, del «signo más subjetivo, que depende en gran medida de la voluntad del autor»; a continuación, establece los usos más habituales, aunque, como suele suceder en este signo, su normativa no es muy precisa:

NORMAS. REVISTA DE ESTUDIOS LINGÜÍSTICOS HISPÁNICOS, NÚMERO 2 (AÑO 2012):

http://www.uv.es/normas

(ISSN 2174-7245). 
- Para distinguir entre sí las partes de un periodo en las que hay alguna coma.

- Entre oraciones coordinadas adversativas, aunque indica que, si se trata de oraciones cortas, basta una simple coma.

- Cuando a una oración sigue otra precedida de conjunción que no tiene perfecto enlace con la anterior (Pero nada bastó para desalojar al enemigo, hasta que se abrevió el asalto por el camino que abrió la artillería; y se observó que uno solo, de tantos como fueron deshechos en este adoratorio, se rindió a la merced de los españoles).

- Cuando después de varios incisos separados por comas, la frase final se refiera a ellos o los abarque y comprenda a todos.

- En las relaciones de nombres, cuando a estos les sigue el cargo u ocupación de la personas (Jack Bell, de «The Associated Press»; Baskin, del «News» de Dallas...).

Sobre los dos puntos, el Libro de estilo establece que señala «una pausa precedida de un descenso en el tono; pero, a diferencia del punto, denota que no se termina con ello la enumeración del pensamiento». A continuación, indica los usos más habituales que, básicamente, son los recogidos en los manuales de ortografía y puntuación. Recuerda, igualmente, que, después de dos puntos, se escribe con minúscula, salvo que lo que siga sea una cita (entrecomillada o no) o una enumeración en varios párrafos, cada uno de ellos precedido por un número o una letra en negra.

Con respecto a las comillas, el Libro señala que deben emplearse solo para encerrar frases reproducidas literalmente. Reconoce que existen otros usos (enmarcar un sobrenombre, subrayar una palabra, destacar un neologismo o un término no castellano), pero indica que, en estos casos, el periódico empleará la letra cursiva.

En el epígrafe 11.31, se establece que el periódico utilizará comillas inglesas o dobles (" "), así como las simples (" '), pero nunca las francesas o angulares (« )). A este respecto, cuando dentro de un entrecomillado vaya otro, el segundo se marcará con comillas simples. En caso de tener que escribir estos dos tipos de comillas juntos, por coincidir al principio o al final de la cita, el Libro señala que deben suprimirse las comillas simples.

El epígrafe 11.34 indica que, en el caso de que en medio de una cita textual se haga una apostilla o aclaración, las comillas han de cerrarse antes del inciso, que irá entre comas, y abrirse después de él ${ }^{3}$.

Ciñéndonos a aspectos periodísticos, se señala que, en los titulares y en los ladillos compuestos en línea aparte, se escribirán entre comillas simples aquellas palabras que, en aplicación del Libro de estilo, hubieran de ir en cursiva. En cambio, los ladillos engatillados, puesto que forman parte del texto (constituyen el inicio del

\footnotetext{
${ }^{3}$ La actual Ortografía (2010: 381), sin embargo, no lo considera necesario. En el apartado 3.4.8.1.1, se indica que, cuando se intercala un comentario del transcriptor de la cita señalando su autoría, este debe enmarcarse entre rayas, sin necesidad de cerrar las comillas para volverlas a abrir después del inciso.
}

NORMAS. REVISTA DE ESTUDIOS LINGÜÍSTICOS HISPÁNICOS, NÚMERO 2 (AÑO 2012)

http://www.uv.es/normas

(ISSN 2174-7245). 
párrafo), se compondrán en el tipo de cursiva que les corresponda. Establece el apartado 11.37 la siguiente regla: «Las comillas simples sustituyen la cursiva en los textos que han de escribirse sin punto final».

Con respecto a los paréntesis y las rayas, el Libro señala que cumplen cometidos similares, pero que los primeros deben reservarse para los incisos acusadamente al margen del relato, y las segundas, para aquellos otros que podrían ir entre comas, pero que las rayas refuerzan y diferencian con toda claridad. También indica que, cuando en un inciso se abra otro, el primero irá entre paréntesis y el segundo, entre rayas.

En cuestiones centradas en el periodismo, el apartado 11.45 indica que nunca se utilizarán paréntesis en los titulares, salvo para dar el resultado de una competición deportiva o para localizar una población que resulte absolutamente desconocida.

Respecto a los signos de interrogación y exclamación, se destaca que, detrás de ellos, nunca se pone punto, pero sí coma o punto y coma. Ahora bien, si al signo de interrogación o exclamación le sigue un paréntesis, una raya o unas comillas, la frase ha de concluir con punto.

El apartado 11.66 recuerda que, si se encierra un signo de interrogación entre paréntesis (en este caso, siempre el de cierre), indica duda; el de exclamación, asombro, y señala explícitamente que ninguna de estas dos formas debe usarse en textos informativos.

Finalmente, se afirma que, cuando una frase sea exclamativa e interrogativa al mismo tiempo, no se duplicarán los correspondientes signos, sino que se abrirá con el exclamativo y se cerrará con el interrogativo.

En relación a los puntos suspensivos, se recuerda que no pueden emplearse después de la palabra etcétera, y que, al final de la frase, hacen innecesaria la inclusión del punto final.

Por último, el Libro también se refiere a la raya, los corchetes, el guion, la barra, el apóstrofo y el asterisco. La actual Ortografía (2010: 400) los considera signos auxiliares, ya que cumplen funciones distintas de las señaladas para los signos de puntuación, y desempeñan, en unos casos, funciones de carácter netamente ortográfico (guion o apóstrofo) ${ }^{4}$ o, en otros, funciones de carácter periférico o simbólico (el asterisco).

Además de este capítulo 11, dedicado exclusivamente a la puntuación, son muchos los apartados que se ocupan de ella a lo largo de todo el libro. Así, en 2.19 se indica que, vaya entre comas o entre paréntesis, no debe suprimirse la preposición de

\footnotetext{
${ }^{4}$ En lo referente al guion, el apartado 11.60 señala que no se empleará el guion entre la partícula ex y otra palabra cuando aquella se utiliza para decir que una persona ya no tiene el cargo o la condición que indica el nombre o adjetivo de persona al que antepone. Como se sabe, en la actual Ortografía se dice que el prefijo ex debe escribirse siempre adherido a la base léxica, como cualquier otro prefijo, salvo si su base es pluriverbal, es decir, consta de varias palabras (ex alto cargo, ex número uno).
} 
delante del número con los años de la persona (Juan López, de 25 años o Juan López (de 25 años), pero no Juan López, 25 años ni Juan López (25 años); en 2.21 se establece que las citas o reproducciones literales de un texto irán entrecomilladas, no en cursiva; en 2.24 se destaca que es una incorrección sintáctica emplear que cuando se hace una cita en estilo directo (Pinochet dijo que «yo voy a garanatizar el orden») y que para expresar las palabras tal como fueron dichas no debe utilizarse el que, y sí los dos puntos y las comillas (Pinochet dijo: «Yo voy a garantizar el orden»); en 4.10, se indica que los ladillos y las firmas no llevan punto final, etc.

\subsection{Libro de estilo de El Mundo (1996)}

En el prólogo al Libro (páginas 13-16), el director del periódico, Pedro J. Ramírez, da cuenta de su proceso de gestación, y señala que se ha intentado combinar la concreción de lo establecido con una flexibilidad en su aplicación, porque «no hay que olvidar que El Mundo es el periódico desde cuyas páginas Francisco Umbral y otros grandes escritores hacen constantes aportaciones innovadoras al idioma, la gramática y hasta la ortografía. Sin un marco de plena libertad de creación nada de eso sería posible». Pero también advierte que hay otros periodistas para quienes el castellano es un mero instrumento de comunicación y para ellos estas normas de redacción y sintaxis pueden facilitarles el trabajo y proporcionar al periódico una homogeneidad básica en las formas.

En cuanto al lenguaje periodístico, el director prefiere que los hechos aparezcan de forma sencilla y huye de «las largas oraciones subordinadas que siempre parecen tener partes sumergidas en el agua». Por eso, pide a sus redactores claridad y concisión, y recomienda un estilo directo, basado en frases y párrafos cortos.

Hace referencia también Ramírez a la poca preparación de los jóvenes periodistas y no duda en arremeter contra ellos señalando que tienen problemas con las concordancias de género y sobre todo de número. «Es todo un síntoma de la deficiente preparación que proporciona nuestro sistema educativo y de las devastadoras consecuencias que para el uso del idioma está teniendo la progresiva sustitución de la cultura literaria por la audiovisual».

El capítulo I trata sobre el estilo y establece que debe ser «claro, preciso, fluido y sencillo», ya que su objetivo se encamina a que el relato resulte fácilmente comprensible para los lectores, huyendo tanto del estilo demasiado literario como del taquigráfico. Señala que es norma general «emplear oraciones simples, separadas por punto y seguido o punto y aparte», y que se debe también «limitar al mínimo posible el recurso a las acotaciones entre rayas o entre paréntesis». Señala, igualmente, que cada «dos oraciones o, como mucho tres, se colocarán puntos y aparte». Sin embargo, no establece ningún criterio para la separación. Es de suponer que, en este caso, se le da 
libertad al redactor para que construya los párrafos siguiendo unos mínimos criterios de coherencia y cohesión, aunque el tratado no apela en ningún momento a estos conceptos. En todo caso, el Libro sigue refiriéndose a criterios cuantitativos, pues establece que los párrafos «de más de diez líneas justificadas son la excepción, no la regla», si bien esta regla puede verse alterada en ciertas crónicas largas, reportajes y artículos de opinión.

En el capítulo IV, se habla de los problemas más frecuentes en la redacción periodística $\mathrm{y}$, entre ellos, se hace una mención explícita a la puntuación incorrecta. Señala que las comas, los puntos y coma y los puntos y aparte «suelen echarse como gravilla sobre los textos, para que caigan al azar». Obsérvese la comparación utilizada («como gravilla») que hace pensar en la poca confianza que se tiene en la pericia lingüística de los redactores. El Libro no establece las reglas básicas de la puntuación y solo dirige su atención hacia dos casos específicos: la coma errónea entre sujeto y predicado (El Madrid, ganó pero no convenció) y la ausencia de coma para suplir el verbo (El PSOE enfurecido con la prensa). No se indica nada, como sí se hacía en el Libro de estilo de El País, sobre los títulos enunciativos que enmarcan un escrito, que no deben confundirse con oraciones con verbo elidido.

En el capítulo V, «Normas de edición», se tratan las cuestiones relativas a los signos de puntuación, en concreto los apartados XIII (comillas), XV (signos ortográficos), XVI (guiones, rayas, signos de «menos») y XVII (corchetes). En relación con los signos ortográficos del apartado XV, el Libro señala que se «aplicarán las normas de la Gramática de la lengua española, de la Academia» y realiza, seguidamente, un recordatorio general sobre los signos más frecuentes.

En lo referente a las comillas, prefiere las de tipo español o romano («»), y, solamente cuando se produzca una cita dentro de otra cita, se admite utilizar las comillas inglesas. Los signos de puntuación colocados al final de una cita textual (puntos, comas, puntos y comas) se situarán siempre después de las comillas, no antes.

En el apartado XV, vuelve a recordar que las comas no separan nunca el sujeto del verbo, y señala que su función principal es la de diferenciar los incisos que suspenden el relato principal sin romper el discurso. Si el inciso rompe claramente ese discurso, precisa, se debe recurrir a las rayas o a los paréntesis. Insiste en que el uso incorrecto de las comas puede cambiar el sentido de una frase y es «un problema frecuente en los periódicos». Ejemplifica con el adverbio «como» (ya visto en el Libro de El País) y con las oraciones adjetivas explicativas y especificativas: «El comandante evitó atacar la loma como ordenaron significa lo contrario de El comandante evitó atacar la loma, como ordenaron. Por otra parte, el uso de la coma particulariza y su ausencia generaliza: Los hombres a los que ella prefiere son sensatos no significa lo mismo que Los hombres, a los que ella prefiere, son sensatos». 
Del punto y coma se dice que es «un signo ambiguo y que debe utilizarse con cuentagotas». Su utilidad estriba en hacer más inteligibles oraciones en las que ya intervienen varias comas (Le aseguró, con la voz entrecortada, que ya no se fiaba de ellos, porque le habían traicionado; que no iba a hacerles más caso, porque le engañaban) y para separar las partes de una relación larga, sobre todo, cuando estas incluyen coma (Tenía tres razones para oponerse a ello: la primera, que le venía mal; la segunda, que nadie se enteraría; la tercera, que podía resultar ilegal).

También se refiere el Libro de estilo de El Mundo al punto (distinguiendo punto y seguido y punto y aparte) y a los dos puntos. De estos últimos se dice que deben emplearse ante una enumeración o para dar paso a una cita textual, y del punto, básicamente, que indica el final de una oración, que las siglas se escriben sin puntos y que los títulos del diario tampoco deben contener este signo. Del punto y aparte, señala que deben separar todas las oraciones que no establezcan un fuerte nexo de relación entre sí y que, por ello, deben ser frecuentes. En los textos informativos, recomienda que el párrafo no supere las veinte líneas.

Se diferencia explícitamente las rayas de los paréntesis, y se señala que ambas sirven para marcar un inciso en la oración, si bien el inciso que se incluye entre rayas rompe menos el discurso que el que se identifica con paréntesis y, por ello, se asemeja más a aquel inciso que se separa sencillamente con comas.

Con respecto a los corchetes, estos se emplean en el diario exclusivamente para introducir en una cita textual palabras no pronunciadas por quien la hizo, pero necesarias para su comprensión o que completan la información que la cita incluye ( $E l$ dirigente rebelde respondió rotundamente a las preguntas de los periodistas: "[Los militares] están acabados, los hemos rodeado) o para introducir en una crónica elementos informativos procedentes de plumas ajenas a la del autor.

En conclusión, el Libro de estilo de El Mundo da indicaciones de carácter general sobre los signos de puntuación, aunque en ocasiones resulta poco preciso. Así, en el apartado «Normas de edición» del capítulo V establece que las normas de edición «se adecuan a las normas de estilo», y que las informaciones más largas e importantes «deben ser troceadas, lo que facilitará la lectura y el diseño de la página». No podemos estar de acuerdo con esta forma de abordar el tema, ya que la facilidad de lectura no viene dada en ningún caso por el hecho de trocear la información, sino por dotar a cada párrafo de una coherencia semántica articulada en un tema único. En este sentido, como señala Figueras (2001), el punto y aparte obliga al lector a tratar el párrafo que ha leído como una unidad de sentido, y le instruye a suponer que el siguiente párrafo forma una unidad de sentido distinta al anterior. 


\subsection{Libro de estilo de ABC (2001)}

Este manual es el que, de entre los consultados, da una información más amplia y precisa sobre los signos de puntuación. En el prólogo, escrito por García Yebra (páginas XV-XVIII), se indica que este Libro de estilo no aspira a ser una preceptiva gramatical, pero en ella «pueden aprender sus lectores mucha gramática española, desde las normas relativas a la acentuación, a la grafía de nombres extranjeros o de palabras de las otras lenguas de España, hasta las que enseñan a dividir las palabras, el uso de las mayúsculas, de las abreviaturas, de las cantidades y de los numerales». También son «muy útiles -sigue diciendo- las páginas dedicadas a puntuación y estilo, con minuciosas instrucciones de carácter práctico, muy bien escritas $\mathrm{y}$, con frecuencia, resumidas en gráficos aclaratorios».

En efecto, el Libro dedica todo un capítulo de 30 páginas al tema de puntuación (páginas 49-83), que denomina «Puntuación y estilo». En este apartado tienen cabida no solo las cuestiones normativas sobre el uso de cada uno de los signos (lo que no lo distinguiría demasiado de otros manuales), sino también cuestiones referentes a la gramática textual, cuadros sinópticos, ejemplos contrastados sobre diversas formas de puntuar, etc. Es decir, nos encontramos ante un verdadero manual práctico que no solamente dicta normas, sino que orienta y aconseja con ejemplos extraídos de la prensa.

Empieza señalando que la puntuación es indicativa, simultáneamente, de la pausa, la entonación y la jerarquización de las ideas que se van produciendo en el texto y en el párrafo, así como de las partes de la oración. Recuerda, también, que la elección de los signos de puntuación no es enteramente libre y personal, ya que está supeditada a la necesidad de transmitir con coherencia y precisión los contenidos, a la vez que permiten estructurar la información y expresar eficazmente estos. Por tanto, nos está diciendo que la puntuación está al servicio del texto para transmitir, por un lado, un contenido informativo y, por otro, una información bien estructurada; es decir, es un elemento tanto de coherencia como de cohesión.

Establece, igualmente, la diferencia entre lengua escrita y lengua oral, afirmando que «el buen escritor no puede ni debe puntuar solo "al oído", porque si se atiene únicamente "a lo que oye" o a lo que "quiere que oiga el lector" corre el riesgo de desaprovechar los recursos de la lengua escrita o de utilizarlos incorrectamente al servicio de un mensaje que está concebido y condicionado de manera diferente al oral».

Antes de abordar cada uno de los signos, el Libro fija conceptos, da una serie de recomendaciones de carácter general y reflexiona acerca de su uso. En primer lugar, distingue entre texto, párrafo y oración, y los caracteriza relacionando la sintaxis con la puntuación. Quiere esto decir que no utiliza criterios cuantitativos, como hacía el Libro 
de estilo de El Mundo cuando hablaba de la necesidad de trocear los párrafos si estos resultaban demasiado largos, sino que se atiene a criterios textuales:

Cada párrafo contiene un bloque informativo, que puede constar de una o más ideas desarrolladas y coorientadas, es decir, argumentativamente orientadas en una determinada dirección común.

Y también a criterios sintáctico-semánticos:

Dentro del párrafo, la información se distribuye en oraciones o frases (simples o complejas). El punto y seguido sirve para delimitarlas separando unidades sintácticas que tienen un sujeto (principal) distinto o que cambian abiertamente el foco de la información.

En segundo lugar, establece una serie de claves para la puntuación de la frase:

Cuando realizamos la frase como una línea no necesitamos puntuarla interiormente; en cambio, cuando la realizamos como una sucesión de segmentos necesitamos delimitar sus diversos componentes, ofrecerle al lector una secuencia legible mediante la puntuación.

Si se tienen dudas acerca de la puntuación de frase, es útil tener en cuenta tres motivos fundamentales por los que acabamos delimitando segmentos en ella:

a) La ruptura en el orden lógico de los elementos de la oración, es decir, si alteramos el orden convencional de sujeto, verbo, complemento directo, indirecto y circunstancial, sobre todo este último.

b) Los fragmentos explicativos, que van siempre entre dos signos de puntuación (comas, paréntesis, rayas..., según corresponda a su situación y su sentido en el contexto).

c) Otras construcciones sintácticas como vocativos, elipsis del verbo, construcciones absolutas, etc.

Por último, se refiere la reproducción literal de palabras o citas y su relación con los corchetes y las rayas.

A pesar de que ya ha establecido algunos usos de los distintos signos de puntuación, el Libro estudia cada uno por separado: la coma, el punto y coma, los dos puntos, los puntos suspensivos, la interrogación, la exclamación, el paréntesis y las rayas (que trata como incisos, comparando el uso de ambos), las comillas (relacionándolas con los procedimientos de cita), otros signos que denomina «auxiliares» (diéresis, apóstrofo, guion, barra) y acaba con unas observaciones sobre el uso de cursiva y de comillas. 
De la coma, establece «los casos más claros», que son similares a los ya descritos en otros manuales y en la Ortografía de la RAE (cuando los complementos preceden al sujeto, incisos, enumeraciones, construcciones absolutas, elisión del verbo, etc.). Cuestión importante en el periodismo son los incisos («explicaciones intercaladas en la frase, con las que el autor se desvía momentáneamente del curso de su exposición»). Al respecto, se establece que su puntuación (coma, paréntesis o rayas) dependerá sobre todo del grado de desvío que expresen respecto al contenido objetivo de la frase. Se reconoce que la elección de uno u otro signo es subjetiva, por lo que no se atreve a dar sino una recomendación de carácter general: «Cuanto más relacionado esté el inciso con el contenido argumentativo del resto de la frase, más tenderá a ir entre comas; cuanto más alejado, más fácilmente aparecerá entre rayas».

El Libro de estilo de $A B C$ precisa que, en el periodismo escrito, lo normal es que ni paréntesis ni rayas aparezcan manipulados con el objeto de dotar de cierta intención o subjetividad al texto (como hace con unos ejemplos ilustrativos del caso). Parece claro que una explicación incluida en una noticia debe considerarse informativamente importante y relacionada y que, en este caso, tendría que ir entre comas. Otra cosa, naturalmente, son los artículos de opinión, en donde el autor dispone de más libertad para aportar su punto de vista.

Del punto y coma, se señala que su función es fundamentalmente «jerarquizadora, indicadora de la trabazón sintáctico-semántica con que el autor presenta la información al lector». Se establece que, al final de un período, el punto y coma y el punto son signos intercambiables, pero se debe tener en cuenta que la información separada por ellos se percibirá como diferente. La diferencia no es de índole sintáctica, sino pragmática y de ligazón discursiva, ya que, con el punto y coma (al contrario de lo que ocurre con el punto), la información que lo precede no se cierra hasta que termina lo que va detrás.

El punto y coma «raramente puede ser sustituido por la coma, ya que cada uno tiene su lugar propio e insustituible en ciertas estructuras sintácticas que requieren, por su tamaño, especial cuidado en el modo en que se transmiten al lector», y prescribe su uso en «períodos extensos (frases largas), ante las conjunciones adversativas pero, sin embargo, aunque, no obstante, con todo, etc.», y, en general, «en períodos extensos, para separar sus distintos miembros cuando estos contienen partes con coma interior».

Con los dos puntos «el autor indica al lector que la interpretación de lo que sigue debe estar subordinada al contenido del enunciado que precede a los dos puntos». Advierte que el enunciado que precede a los dos puntos comienza y acaba sintácticamente antes del signo, y el que sigue debe terminar con puntuación fuerte (con punto y coma, punto o equivalente; pero no con coma).

Los fallos más frecuentes que observa el Libro en la utilización de los dos puntos son los siguientes:

NORMAS. REVISTA DE ESTUdIOS LINGÜÍSTICOS HISPÁNICOS, NÚMERO 2 (AÑO 2012):

http://www.uv.es/normas

(ISSN 2174-7245). 
1. Cuando se utilizan después de preposición o de la conjunción que.

2. Cuando se incluye dentro de los dos puntos información que debe estar contenida en otro bloque. Pone el siguiente ejemplo: Primero hizo todo lo que le había ordenado: terminó el muro, pintó la cerca, puso la puerta en su sitio y decidió irse sin que nadie lo notara. Obsérvese que «decidir irse» no se le había ordenado: corresponde a otro bloque informativo.

A continuación enumera los usos correctos, lo que viene a ser una reproducción, en líneas generales, de lo ya establecido por la ortografía académica y por otros libros de estilo: cuando entre las dos partes se establece una relación explícita mediante algún término o expresión que anticipa (si está antes) lo que viene a continuación o repite (si va tras los dos puntos) lo anterior; antes de las conclusiones, consecuencias o resúmenes (sin nexo); y para introducir una cita textual directa.

Respecto a los puntos suspensivos, se señala que son un signo «poco usado en periodismo escrito y que su aparición suele restringirse a escritos de opinión, donde "dejar de decir algo" intencionadamente o "suspender momentáneamente" lo que se está diciendo puede enriquecer la comunicación con el lector». Recuerda que no pueden usarse después de etc. (o etcétera), por tratarse de una redundancia, y que deben ir entre corchetes cuando indican, en el interior de una cita, que falta algo en ella.

De los signos de interrogación y exclamación se indica que, frente a otros signos como el punto, la coma, el punto y coma, los dos puntos y los puntos suspensivos, que son signos «sintácticos», estos son esencialmente entonativos, modales, que pueden aplicarse a una frase completa o solo a una de sus partes. Si aparecen entre paréntesis detrás de una palabra, sintagma u oración, indican ironía, duda, sorpresa, necesidad de cuestionarse lo dicho por motivos de fondo, de forma, de fiabilidad de la fuente, etc. Si se utilizaran para intervenir en un texto ajeno, aclara, habría que encerrarlos entre corchetes: [?], [!].

También aborda este trabajo lo que la autora denomina estilo periodístico de la puntuación. En este sentido, se señala que la puntuación, como es sabido, ha de estar acorde con la estructura sintáctico-semántica construida y que se han de utilizar «los signos de puntuación necesarios, pero ni uno más». Pero tampoco escapa a nadie que la puntuación tiene que ver con el estilo que se pretende crear (más o menos trabado) y que, en ocasiones, esto puede llevar a intentar ofrecer una información sesgada o subjetiva. Dejando a un lado lo que es opinión y centrándose en lo exclusivamente informativo, el Libro de estilo de $A B C$ aconseja que la puntuación, además de correcta, «preserve la información de posibles interpretaciones o atribuciones subjetivas».

Como vemos, el Libro de estilo de $A B C$ es, entre los libros analizados, el que más precisiones y reflexiones lleva a cabo sobre el uso de los signos de puntuación, e intenta demostrar que la buena utilización de estos va más allá de la normativa y entra en 
relación, por un lado, con la cohesión interna del texto y, por otro, con el estilo y la objetividad que toda noticia periodística demanda.

\subsection{Libro de Estilo Vocento (2003)}

Este trabajo, realizado por Martínez de Sousa, indica que, aunque un libro de estilo es normativo por definición, «su función no va a ser la de explicar en detalle todas y cada una de las normas ni la de compararlas con otras que pudieran ser mejores o peores, sino de elegir, entre las existentes, las aplicables a casos concretos en función de una forma de interpretar los hechos gráficos y morfológicos del lenguaje en todas sus manifestaciones». Dedica a la ortografía la segunda parte (en donde se incluye la puntuación), si bien en la primera - centrada en los principios generales tanto deontológicos como estilísticos- hay alguna referencia al tema que nos ocupa. Así, en el epígrafe 1.3.2.2, señala que, en aras «de la claridad que debe caracterizar el estilo periodístico, han de utilizarse frases cortas, y que deben evitarse, en lo posible, las frases subordinadas». En 1.3.2.6, al referirse a la amenidad del estilo periodístico, señala que una buena puntuación «hace más fluida y fácil la lectura», y vuelve a recordar que las frases cortas «ayudan a la claridad, al igual que los párrafos breves». En 1.3.3.3, señala que los títulos no deben llevar signos de puntuación, excepto las comas ineludibles, aunque — en todo caso - es preferible siempre el titular sin coma. Recuerda que no están permitidos, en general, los titulares de forma interrogativa, ya que la información sirve para responder a las preguntas del lector, no para suscitarlas. En este mismo epígrafe hace referencia al párrafo y señala que todos deben ser completos y tener sentido por sí mismos, de manera que la comprensión no quede incompleta si se deja de leer en cualquier momento.

En el capítulo 2 (lenguaje y ortografía), se recogen una serie de materias colocadas por el orden alfabético de sus respectivas denominaciones. Se divide en tres secciones, y, en la primera de ellas (morfología y lenguaje), tienen entrada los signos objeto de este estudio.

Hay una entrada general con el nombre de «signos de puntuación» ${ }^{5}$. Se señala explícitamente que estos signos sirven para indicar las pausas y el sentido del texto. Son el punto, la coma, el punto y coma, los dos puntos y los puntos suspensivos, y añade que sus usos se explican en las respectivas entradas en esta sección del libro. Esto se cumple para todos los signos, excepto para el punto, en donde no encontramos ninguna entrada,

\footnotetext{
${ }^{5}$ Sigue aquí la clasificación realizada por él mismo (Martínez de Sousa, 2001) en su Manual de estilo de la lengua española: signos ortográficos diacríticos (los que se añaden a una letra, una palabra o un grupo de palabras para distinguirlos de otros de igual grafía y distinta función o significado); signos ortográficos auxiliares (los signos que tienen una determinada función ortográfica que no es diacrítica ni sintagmática), y signos ortográficos sintagmáticos (los que afectan a la frase u oración), que son los de puntuación, los de entonación y los signos auxiliares de la puntuación.
}

NORMAS. REVISTA DE ESTUDIOS LINGÜÍSTICOS HISPÁNICOS, NÚMERO 2 (AÑO 2012):

http://www.uv.es/normas

(ISSN 2174-7245). 
si bien hay numerosas referencias cuando habla de las abreviaturas, las siglas o los titulares. En relación a estos últimos, recomienda no emplear signos y usar solo la exclamación, la interrogación y los dos puntos en títulos que sean citas (Aznar: ";Lo pagarán!»). Si acaso, pueden emplearse paréntesis para encerrar resultados deportivos o unidades geográficas administrativas que sitúen un topónimo desconocido.

Martínez de Sousa distingue los signos de puntuación anteriores de los «signos de entonación», con una entrada distinta, que define como signos sintagmáticos dobles que sirven para dar la entonación que convenga a una palabra, frase u oración. Son la interrogación y la exclamación. Por último, da entrada a los «signos auxiliares de la puntuación», que son signos sintagmáticos (por tanto, dobles en todos los casos) que sirven para dotar de cierto sentido a una palabra, sintagma, oración o periodo. Son las comillas, los corchetes, los paréntesis, la raya y el signo de menos.

Distingue los anteriores de los «signos auxiliares generales», que son una serie de signos ortográficos de variadas funciones que no son diacríticas ni sintagmáticas. Entre los signos auxiliares generales, nombra el asterisco, la barra, la barra doble, la barra inversa o antibarra, el calderón, la cruz, la cruz doble, el et, la flecha, el guion, el igual, la llave, la manecilla, el párrafo, la pleca, la pleca doble, el por mil, el porcentaje, el punto alto o medio y los puntos encorchetados.

Como se ha dicho anteriormente, cada uno de los signos tiene una entrada individual en el capítulo. Respecto a la coma, establece en trece puntos los usos más habituales de este signo, incluyendo la llamada coma decimal para separar los enteros y los decimales en una cantidad, los grados y sus fracciones, las décimas, centésimas y milésimas de segundo en las expresiones horarias cuando expresan tiempo invertido en

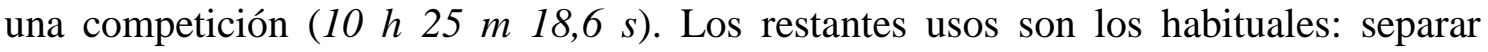
elementos de una oración, en los incisos, en las oraciones de relativo explicativas o aclarativas, en las oraciones en que se invierte el orden normal de los elementos oracionales, en las aposiciones situadas después de un nombre que designan la misma realidad que este nombre, en las cláusulas absolutas, cuando se omite un verbo ya mencionado, etc. No queda muy claro, a nuestro juicio, el uso de la coma delante de la conjunción $y$; dice literalmente el Libro: «Si tres o más oraciones van unidas por conjunción, es normal separarlas con coma: Sale el sol, y el campo se alegra, y el hombre se siente alegre y feliz». En este sentido, el Libro de estilo de ABC era más explícito en el uso de este signo ante conjunción copulativa.

Respecto a los dos puntos, indica que se usan para separar el antecedente del consecuente (En resumen: soledad y aburrimiento); para separar una oración de otra en que se expone lo que en la primera se enuncia (La semana tiene siete dias: lunes, martes...); para separar una oración de la explicación que le sigue, a modo de resumen o consecuencia (Muerte, desolación, destrucción total: esto es la guerra); para introducir citas textuales (Dice Cervantes: «En un lugar de la Mancha»), y, por último, después de las fórmulas de cortesía y otras semejantes en las cartas y textos similares (Querido amigo, Expone, Dice...). 
En relación al punto y coma, no hay indicaciones subjetivas, como ocurría con los libros de El Mundo y de $A B C$, sino que, simplemente, se limita a establecer cuatro usos que - pensamos - no resultan demasiado esclarecedores. Así, señala que el punto y coma se utiliza para separar los miembros de alguna extensión en una cláusula. No podemos estar de acuerdo con esta afirmación, ya que resulta muy ambigua la expresión «alguna extensión». Cita el siguiente ejemplo: Mirar por los intereses de la empresa; salvaguardar los de sus empleados; tratar de elevar la producción; aumentar en lo posible el ritmo de ventas, y, finalmente, armonizar los intereses sociales con los empresariales. Cabe preguntarse si las cláusulas tienen la suficiente extensión para separarse con punto y coma, máxime cuando no contienen otros signos en su interior. En segundo lugar, señala que se utiliza el punto y coma para «separar oraciones sueltas de sentido cabal», y pone el siguiente ejemplo: Marisa es casi de la familia; cuida, pues, de ella. En todo caso, tendría que haber aclarado que entre las dos oraciones «de sentido cabal» no debe haber relación de causa o consecuencia, ya que en ese caso convendría poner dos puntos. En tercer lugar, para separar entre sí oraciones elípticas, como por ejemplo París tiene unos ocho millones de habitantes; Londres, siete; Nueva York, dieciséis, y Tokio, doce. Aclara que las dos últimas oraciones, al ir enlazadas por la conjunción $y$, solo requieren coma, puesto que en estos casos la coma, si precede a $y$, equivale al punto y coma con que se separan las oraciones anteriores. Por último, señala que se debe utilizar el punto y coma antes de los términos en efecto, por último, sin embargo, no obstante, por ejemplo, verbigracia y otros. Precisa que la expresión a saber puede ir precedida de este signo o de solamente una coma, y le puede seguir coma o dos puntos, según los casos; por otra parte, la voz pero puede ir precedida de punto y coma o coma (e incluso punto), pero solo irá seguida de coma si le sigue un inciso.

Sí que hay indicaciones, bastante extensas y precisas, acerca de las comillas. Distingue, en principio, dos tipos de comillas: dobles y simples o sencillas. Dentro de las primeras, distingue entre latinas, españolas o francesas («»); inglesas (“ "), y mecanográficas (" "). Las simples o sencillas pueden ser latinas, españolas o francesas ( $८$ ); inglesas (' '), y mecanográficas (' '). Establece que el orden de uso de las comillas debe ser el siguiente: primero se usan las comillas dobles latinas; dentro de ellas, las dobles inglesas; dentro de estas, las sencillas, y, si se presenta la necesidad de otro nivel, las simples latinas o angulares. Estas últimas, señala el Libro, surgen con la informática y tienen empleo en algunos diccionarios y textos semejantes con funciones específicas.

A continuación, establece el empleo de cada una de las comillas indicadas. Reproducimos aquí brevemente lo dicho sobre las comillas dobles latinas, que son las más usuales. Se utilizan para encerrar citas en lo escrito, para sustituir a la raya de los diálogos cuando estos se escriben dentro del párrafo y para poner de relieve una palabra o frase que se refiere a algo escrito o dicho textualmente (El ministro rechaza «tajantemente» las imputaciones). También se utilizan los dos puntos para poner de relieve los títulos de artículos, reportajes o noticias; para señalar palabras o frases que 
encierran ironía o segunda intención; para reproducir, en obras literarias, los pensamientos de los protagonistas, etc. También señala los casos en los que no deben usarse las comillas; en concreto, cita tres: en las denominaciones de compañías, entidades, empresas, etc., aunque estén escritos en idioma extranjero; en los títulos de los libros de la Biblia, y en los versos intercalados en una cita, aunque pertenezcan a autor distinto del citado. Por último, da una serie de normas sobre la utilización de las comillas cuando coinciden con otros signos.

Sobre los puntos suspensivos establece tres usos: cuando se omite algo que se sobrentiende o se quiere dejar el pensamiento en suspenso; para producir temor, duda, y en lugar de la abreviatura etc. o de la palabra etcétera. Señala también que los puntos suspensivos no admiten tras sí el punto final.

En relación a los signos de exclamación e interrogación, además de reproducir lo visto en otros tratados ya analizados, matiza que en los casos en que una pregunta preceda a otra, es la segunda la que lleva los signos (Cuántos hijos tiene María, ¿tres o cuatro?) y que una frase interrogativa o exclamativa no puede llevar dos oraciones separadas por punto. Así, no es correcto escribir ¡No. No voy!, sino que la forma correcta es ;No! ¡No voy!

Respecto a los paréntesis, hay alguna interesante observación en relación a si se debe colocar el punto antes o después del paréntesis. Así, señala que cuando una oración o periodo entre paréntesis comienza párrafo o va después de punto, el punto final que le corresponde se pone dentro del paréntesis de cierre, pero si no es así, los signos de puntuación correspondientes a la oración anterior a la apertura de paréntesis habrán de colocarse detrás del paréntesis de cierre.

Hay indicaciones también sobre corchetes y puntos encorchetados [...], este último para indicar, en una cita directa, que el citador omite ciertos pasajes del texto original que no le interesa reproducir. Señala, igualmente, que es un error encerrar los tres puntos entre paréntesis para este fin ${ }^{6}$.

En relación a la raya, indica que, con la aparición de la informática y la autoedición, se ha creado una variante que equivale aproximadamente a la mitad de la raya, y que por su longitud parece más adecuado llamarla menos. A continuación, establece los usos más frecuentes, entre los que incluye su utilización en los diálogos y para evitar la repetición del autor en las bibliografías, aunque, a nuestro juicio, es difícil encontrar estos casos en los diarios. También establece su uso para acotar oraciones incidentales, «con un matiz que distingue su empleo del uso de los paréntesis o las comas en casos iguales o semejantes», si bien no indica nada sobre ese «matiz», como sí lo hacía el Libro de $A B C$, que reflexionaba sobre los incisos y el grado de «desvío» de la información principal.

\footnotetext{
${ }^{6}$ Recordemos que la Ortografía, en su punto 3.4.10.2.e), señala que, entre corchetes [...] o, menos frecuentemente entre paréntesis (...), los puntos suspensivos indican la supresión de una palabra o un fragmento de una cita textual (Ortografía, 2010: 397).
} 
Por último, en la segunda parte del capítulo 2, realiza indicaciones de cómo han de utilizarse los signos de puntuación (punto, coma, punto y coma, dos puntos y puntos suspensivos) en conjunción con signos dobles (comillas, paréntesis, corchetes, signos de interrogación y exclamación), y también sobre cómo debemos escribirlos cuando entran en conjunción con signos en cursiva.

En definitiva, el Libro de estilo Vocento da una información precisa sobre los signos de puntuación, si bien peca de ambigüedad o poca precisión en la explicación de algunos de ellos (el punto y coma) y no ofrece apenas información sobre el uso del punto y aparte.

\section{LOS SIGNOS DE PUNTUACIÓN EN LOS MEDIOS ORALES}

Muchos expertos opinan que basar la puntuación en criterios prosódicos es una fuente constante de errores (coma entre sujeto y predicado, falta de comas en los incisos, etc.). Pero no podemos obviar completamente los elementos prosódicos, puesto que las unidades sintácticas y discursivas delimitadas por los signos corren paralelas muchas veces a las unidades fónicas, si bien conviene no confundir ambos fenómenos. Como señala acertadamente la nueva Ortografía (2010: 288), la puntuación y los elementos prosódicos son sistemas paralelos, pero no por ello puede decirse que uno refleje el otro. Los medios de comunicación orales también estudian los signos de puntuación, y lo hacen desde su propia perspectiva, es decir, señalando las aportaciones que la puntuación realiza a la lengua oral.

\subsection{Redacción y locución en medios audiovisuales: la radio (1999)}

Huertas y Perona (1999) señalan dos razones principales por las que es difícil hablar de los signos de puntuación en el ámbito de la redacción radiofónica. La primera tiene lugar porque la necesidad de adecuar la redacción al código oral conlleva que estos signos no puedan aplicarse de la misma manera que a un texto estrictamente escrito. Por ello, en el relato radiofónico se pueden ubicar signos en lugares donde resultan incorrectos desde el punto de vista gramatical con el único fin de provocar una locución adecuada que facilite la comprensión. Así pues, unidades fónicas y unidades gramaticales no son siempre coincidentes.

En segundo lugar, el oyente no visualiza el texto y, consecuentemente, tampoco los signos, por lo que el locutor ha de transmitirlos mediante la enunciación. Esto implica que todo signo se ha de interpretar en la transcripción oral (por ejemplo, mediante una pausa o un cambio en la velocidad de lectura). Todo ello obliga a prestar

NORMAS. REVISTA DE ESTUDIOS LINGÜÍSTICOS HISPÁNICOS, NÚMERO 2 (AÑO 2012):

http://www.uv.es/normas

(ISSN 2174-7245). 
atención a su uso, pues un signo mal colocado o ausente puede generar problemas de descodificación.

La coma y el punto son los signos de puntuación que más se usan en los textos radiofónicos. Habitualmente, actúan como separadores, por lo que suelen traducirse en la locución por una pausa que marca también el sentido del mensaje. El locutor, afirman estos dos autores, cada vez que ve una coma o un punto, se ve obligado a hacer una pausa, aunque conviene aclarar algunas cuestiones:

a) En ocasiones, si se quiere transmitir un estado de ánimo que implique un número reducido de pausas (por ejemplo, nerviosismo), puede ser conveniente no marcar el texto con signos, aunque no sea correcto desde un punto de vista gramatical.

b) Hay pausas que no se corresponden con los signos de puntuación. El locutor puede estar interesado en prolongar una pausa, sin que ello signifique necesariamente que se haya de escribir un signo de puntuación (por ejemplo, una coma).

En definitiva, lo que Huertas y Perona intentan transmitir en este manual de redacción y locución es que lo importante en la radio es marcar en el papel aquellas pausas que dan al texto el sentido pretendido y eliminar otras que no resultan pertinentes. Esta señalización puede hacerse mediante la coma y el punto, pero también mediante cualquier otro signo, como puede ser una barra inclinada (/). Por tanto, más que de signos de puntuación, en la radio estaríamos hablando de signos de transcripción del discurso oral, ya que se podría utilizar / para una pausa menor y /// para una mayor.

También hacen referencia estos autores a los puntos supensivos, y establecen que, aunque no son de uso tan habitual como la coma y el punto, pueden emplearse por tener «una clara traducción oral». Consideran que los puntos suspensivos son difíciles de transmitir sonoramente, tanto los que se emplean para dejar una oración incompleta, porque pueden pasar inadvertidos al oyente si el locutor no los acompaña de una entonación en suspenso, como los que indican temor o duda, que requieren de un especial tratamiento en la locución.

Del punto y coma y los dos puntos, consideran que son «poco recomendables». El primero debido a que la gramática recomienda su uso en frases largas, y estas deben evitarse en la redacción radiofónica. Con respecto a los dos puntos, «estos suelen implicar una excesiva concentración de datos en un espacio de tiempo muy breve, lo que perjudica el proceso de comprensión oral», y, por tanto, lleva a rehusar este signo. Cita expresamente el caso de los dos puntos para dar entrada a una explicación o a un resumen, recurso muy extendido en los medios impresos, pero que en radio «solo sirve para crear textos poco inteligibles y con una locución que se parece más a una lectura en voz alta que a un texto hablado». 
Tampoco se justifican en el medio radiofónico el paréntesis y los guiones, cuya función es introducir una frase aclaratoria o incidental con escasa conexión con la anterior y posterior. Consideran que la idea adicional aportada entre estos signos interrumpiría la lectura de la frase y perjudicaría la comprensión de la misma. Como esta situación no debe darse en el texto radiofónico, si consideramos esa información imprescindible, se le tendría que dedicar otra frase o párrafo independientes.

En relación a las comillas, se señalan varios usos, entre los que destaca el que se hace para distinguir una palabra del resto con el objeto de que el lector le preste una atención especial y la interprete con un matiz irónico o metafórico. En estos casos, es la locución la que debe marcar el sentido, ya que es «la manera de que el oyente perciba el sentido del mensaje. No basta con plasmar las comillas sobre el papel, si estas no son transcritas oralmente al destinatario». En el mismo caso están las comillas que sirven para enmarcar las citas textuales, pues es el locutor el que debe transmitir al receptor que se trata de una cita exacta a la original. Hace también referencia a otros usos, no recogidos en la Ortografía (remarcar títulos, películas, certámenes, etc.), y recuerda que, en estos casos, «el objetivo es siempre que el oyente interprete el mensaje tal y como es, por lo que el locutor habrá de remarcar en su locución una diferencia entre lo que corresponde al título y lo que no». Recuerda que la audiencia no ve las comillas plasmadas sobre el texto escrito, sino que «las ha de escuchar», por lo que recomienda sustituirlas por recursos verbales que marquen claramente el comienzo y el fin de las palabras que engloba.

Respecto a los signos de interrogación y admiración (sic), recomienda colocarlos al principio y al final de las oraciones, incluso en las lenguas donde gramaticalmente es incorrecto colocarlo al principio, para marcar correctamente el cambio de entonación de las proposiciones.

Como vemos, las normas de uso de los signos de puntuación contenidas en este manual de redacción y locución del medio radiofónico no se atienen a las normas gramaticales y atienden principalmente a los dos elementos prosódicos más importantes: por un lado, las pausas, que — como hemos visto- pueden deberse a factores personales o de intención comunicativa, y que no siempre tienen su reflejo gráfico; y, por otro, la entonación, que marca la curva melódica con la que se pronuncian los enunciados.

\subsection{Manual de estilo de TVE (1993)}

En la presentación de este manual (páginas 9-10), se hace hincapié en la importancia que tienen los medios de comunicación a la hora de difundir el idioma y también sus incorrecciones. «Quizá somos muchos los responsables del uso y deterioro de la lengua española, pero creo que quienes redactan para la televisión y hablan en ella tienen ya multiplicado el coeficiente de esa responsabilidad». Por eso considera 
imprescindible la correcta expresión gramatical y la existencia de este manual, que no solo resuma lo sustancial de la materia sino que también permita considerarlo «un libro, un cuaderno que sirva para hacer acotaciones que nos ayuden a cuantos hacemos televisión a mejorarnos día a día en el uso del lenguaje, de la lengua española».

Lázaro Carreter, en el breve prólogo que firma (páginas 11-12), insiste en la necesidad de que los medios de comunicación presten una atención primordial al lenguaje. Piensa que esto ya está ocurriendo y de ello son prueba los libros de estilo publicados. Confía en que los informadores les hagan caso, aunque disientan de las soluciones que tales libros propugnan. Afirma Lázaro Carreter haber examinado con mucha complacencia el Manual y encontrarlo «sumamente adecuado al fin que se propone». Por último, el lingüista, que tanto se ocupó del lenguaje en los medios de comunicación, lanza un deseo que, ciertamente, está muy lejos de cumplirse: «Ojalá se perciban pronto sus frutos, y que el lenguaje de televisión pueda convertirse algún día en canon del idioma como ocurre en otros países».

El Manual de estilo de TVE dedica el capítulo II a la redacción y el estilo, batiburrillo donde tienen cabida cuestiones tan dispares como el acento, el adjetivo, el adverbio, el artículo, el género, el gerundio, las preposiciones, el que, los verbos y la voz pasiva, y en el que se reserva un hueco a los signos de puntuación. En concreto, examina la coma, las comillas, los dos puntos, el guion, los signos de interrogación y admiración, los paréntesis y el punto. Es curioso que no haga referencia al punto y coma, tal vez el signo más problemático. Recordemos que el Libro de estilo de El País decía que era «el signo más subjetivo, que depende en gran medida de la voluntad del autor», y el del diario El Mundo, que constituía un «híbrido que marca una pauta más marcada que la de la coma y puede separar dos oraciones como un punto, es un signo ambiguo y que debe utilizarse con cuentagotas». Las indicaciones que da el Manual sobre el uso de estos signos es bastante escueta y puramente normativa, ya que se limita a prescribir usos correctos e incorrectos.

Es curioso que, cuando se está regulando el uso de la coma, no se haga referencia a las pausas, en un medio en donde se verbaliza el texto escrito.

El signo de los dos puntos «se marca en el lenguaje hablado con una bajada de tono de voz y con una pausa». Establece cuatro usos correctos, el primero de los cuales no aparece reflejado en el Libro de El País ni en el de El Mundo, y solo como cuestión secundaria en el de $A B C$. Son los siguientes:

a) Después del encabezamiento de una carta.

b) Cuando se citan palabras textuales.

c) Antes de la oración en que se saca una conclusión o se presenta la causa de lo que acaba de decirse. 
d) Delante de una enumeración.

Del punto dice que exige «hacer en la lectura una pausa mayor que después de la coma $^{7}$ o del punto y coma, aunque de duración variable de acuerdo con el sentido del texto». La instrucción, como vemos, es bastante ambigua, pues no sabemos a lo que se refiere con «el sentido del texto».

Sigue diciendo que, en general, se usa este signo «para indicar que ha finalizado un párrafo o una frase que se consideran completos $\mathrm{y}$, por lo tanto, son perfectamente comprensibles».

A continuación, establece la diferencia entre punto y seguido y punto y aparte; lo hace con criterios puramente gráficos, pues señala que, después del punto y seguido, «el texto continúa en la misma línea o en la siguiente, sin espacio en blanco», y aclara que, en este último caso, «la pausa no rompe la relación que guardan los párrafos contiguos». No se entiende muy bien lo que se quiere indicar aquí, ya que el párrafo siempre debe quedar delimitado por el punto y aparte, pero, en ningún caso, con un punto y seguido. Del punto y aparte dice que «implica mayor independencia de las cláusulas por él separadas, y exige una pausa más larga que el punto y seguido». De nuevo, como ocurría también en el Libro del diario El Mundo, no se tienen criterios claros para delimitar los párrafos. Del punto final señala que cierra el texto, y precisa que se debe decir «punto final» y no «punto y final», como se dice erróneamente.

Por último, en la regulación de las comillas se puede ver la relación entre los signos de puntuación y la especificidad del medio en que se insertan. Así, señala el Manual que, en escritos destinados a la televisión, no bastan las comillas: «Es conveniente añadir la aclaración: $X$ dijo textualmente, u otra semejante».

Del mismo modo, «debe evitarse también la práctica, bastante frecuente, de entrecomillar determinadas palabras para indicar que se permite uno la licencia de emplearlas, aunque no sean muy propias, o de atribuirles cierto sentido distinto a su significado literal. Aunque en los textos escritos sea un recurso aceptable, en la televisión no tiene cabida, dada la evidente dificultad de indicar con distinta entonación de voz que la palabra va entrecomillada».

\section{CONCLUSIONES}

Hemos visto que los libros de estilo periodísticos dedican un espacio considerable a regular el uso de los signos de puntuación, pues los consideran un tema que contribuye a organizar y jerarquizar la información que debe darse al lector o

\footnotetext{
${ }^{7}$ Recordemos que nada ha establecido sobre la relación entre coma y pausa.
} 
espectador. En los libros de estilo estudiados se repasan las normas fundamentales que regulan cada uno de los signos y se hace mención a los usos específicos en el medio periodístico (la puntuación en los titulares, en los ladillos, en los pies de fotografías, etc.). Igualmente, se hace hincapié en aquellos usos erróneos que afectan al lenguaje periodístico y que pueden tergiversar el contenido de la noticia (comas en oraciones explicativas, coma tras el adverbio como, uso de las comillas, etc.). De los libros analizados de la prensa escrita, es el Libro de estilo de $A B C$ el que más incide sobre la utilidad de los signos de puntuación, al reflexionar acerca del estilo de la escritura y de la legibilidad del texto. También señala este libro que mediante la puntuación puede ofrecerse una información sesgada, por lo que aconseja que esta, además de ser correcta, preserve la información de posibles interpretaciones subjetivas.

Por otro lado, hemos analizado también el tratamiento que los medios de comunicación orales realizan de la puntuación. Es este un tema controvertido, por cuanto la puntuación siempre se da en el texto escrito y estos medios transmiten oralmente la información, con lo que se pueden originar ciertas confusiones al mezclar aspectos prosódicos y sintácticos. No obstante, los medios orales son conscientes de que la mala colocación de un signo o su ausencia también puede generar problemas de interpretación, por lo que conviene dar orientaciones acerca de su buen uso.

\section{REFERENCIAS BIBLIOGRÁFICAS}

AlezA IZQUIERDO, Milagros, coord. ${ }^{\text {, }}$ et alii (2006): Lengua española para los medios de comunicación: usos y normas actuales, Valencia, Tirant lo Blanch.

CATACH, Nora (1994): La ponctuation (Historie et système), Paris, Presses Universitaries de France (Col. Que sais-je?).

CEBrián, Juan Luis (1981): ¿Qué pasa en el mundo? Los medios de comunicación de masas, Barcelona, Salvat.

El Mundo (1996): Libro de estilo, Unidad Editorial, Madrid.

El PAís (2002): Libro de estilo, Madrid, El País/Santillana.

FERnÁndez De BeAumont, José (1987): El lenguaje del periodismo moderno: los libros de estilo en la prensa, Madrid, SGEL.

FERNÁNDEZ MARTÍNEZ, Pilar, coord. a (2003): Lengua y comunicación: norma frente a uso, Madrid, Universitas.

FIgUeras, Carolina (2001): Pragmática de la puntuación, Barcelona, Octaedro/EUB. 
FundaCión DEL ESPAÑOL URGENTE (2009): Manual del Español Urgente, Madrid, Cátedra, Decimoctava edición corregida del Manual de Estilo de la Agencia EFE. En línea: 〈http://www.fundeu.es>.

GómEZ FONT, Alberto (2001): «Los libros de estilo en los medios de comunicación en español: necesidad de un acuerdo». ELE Espéculo, 1-11. En línea: <http://www.ucm.es/info/especulo/ele/g_font.html $>$.

GómeZ SÁnCHEZ, M. ${ }^{a}$ Elena (2008): «El español en la prensa: aspectos ortográficos», en Arroyo Almaraz, Antonio, coord., La lengua española en los medios de comunicación y en las nuevas tecnologías, Madrid, Ediciones del Laberinto, 15-66.

GÓMEZ TORREGO, Leonardo (2011): Ortografía del español actual, Madrid, SM.

Grijelmo GarcíA, Álex (2008): El estilo del periodista, Madrid, Taurus. UOP.

HALliDAY, Michael Alexander (1985): Spoken and Written Language, Oxford,

Huertas Bailén, Amparo y Juan José Perona PÁez (1999): Redacción y locución en medios audiovisuales: la radio, Barcelona, Bosch.

LAVILla Uriol, María José (2003): «Las gramáticas y los manuales de estilo: normas y uso en cuestiones morfosintácticas del español. Estudio del gerundio», en

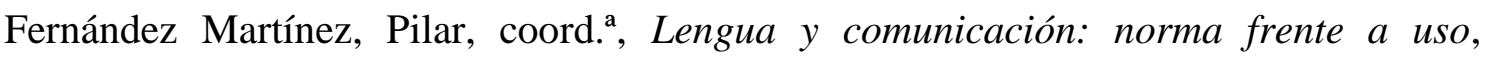
Madrid, Editorial Universitas, 69-77.

MARTínez De SousA, José (2007): Manual de estilo de la lengua española, Gijón, Trea, 3. ${ }^{a}$ ed. (MELE 3).

Martínez De SousA, José y Grupo Vocento (2003): Libro de Estilo Vocento, Trea, Gijón.

Mendieta, Salvador, Fernando LÁzAro CARreter y Valentín García Yebra (1993): Manual de estilo de TVE, Barcelona, Labor.

Millán Chivite, Alberto (1997): «Ortología y ortografía: dos disciplinas normativas en permanente interrelación», en Cantero, Francisco José, Antonio Mendoza y Celia Romea, eds., Didáctica de la lengua y la literatura para una sociedad plurilingüe del siglo XXI, Barcelona, Universitat de Barcelona, 1107-1112.

PEÑAlVer CASTILlo, Manuel (2009): Estudios sobre ortografía y gramática del español, Lugo, Axac.

REAL ACADEMia EsPañola y AsOciación DE ACADEMIAS DE LA LENGUA ESPAÑOLA (2010): Ortografía de la lengua española, Madrid, Espasa.

REAl ACADEMIa EsPañola y Asociación dE ACADEMIAS DE LA LENGUA ESPAÑOLA (2005): Diccionario panhispánico de dudas, Madrid, Santillana. 
ROMERO GUALDA, M. ${ }^{\mathrm{a}}$ Victoria, coord. ${ }^{\mathrm{a}}$ (2002): Lengua española $y$ comunicación, Barcelona, Ariel.

ROSELlÓ VERDEGUER, Jorge (2008): «El aprendizaje de los signos de puntuación a través de los libros de estilo», Textos, 49, 111-121.

TelemAdRID (1993): Libro de estilo de Telemadrid, Madrid, Telemadrid.

Vigara Tauste, Ana María (2001): Libro de estilo de ABC, Barcelona, Ariel. 